\title{
Pharmacogenetics of hepatitis C: transition from interferon-based therapies to direct-acting antiviral agents
}

This article was published in the following Dove Press journal:

Hepatic Medicine: Evidence and Research

24 June 2014

Number of times this article has been viewed

\author{
Sanaa M Kamal ${ }^{1,2}$ \\ 'Department of Medicine, Division \\ of Hepatology, Gastroenterology \\ and Tropical Medicine, Ain Shams \\ Faculty of Medicine, Cairo, Egypt, \\ ${ }^{2}$ Department of Medicine, Salman \\ Bin Abdul Aziz College of Medicine, \\ Kingdom of Saudi Arabia
}

\begin{abstract}
Hepatitis $\mathrm{C}$ virus (HCV) has emerged as a major viral pandemic over the past two decades, infecting 170 million individuals, which equates to approximately $3 \%$ of the world's population. The prevalence of HCV varies according to geographic region, being highest in developing countries such as Egypt. HCV has a high tendency to induce chronic progressive liver damage in the form of hepatic fibrosis, cirrhosis, or liver cancer. To date, there is no vaccine against HCV infection. Combination therapy comprising PEGylated interferon-alpha and ribavirin has been the standard of care for patients with chronic hepatitis $\mathrm{C}$ for more than a decade. However, many patients still do not respond to therapy or develop adverse events. Recently, direct antiviral agents such as protease inhibitors, polymerase inhibitors, or NS5A inhibitors have been used to augment PEGylated interferon and ribavirin, resulting in better efficacy, better tolerance, and a shorter treatment duration. However, most clinical trials have focused on assessing the efficacy and safety of direct antiviral agents in patients with genotype 1, and the response of other HCV genotypes has not been elucidated. Moreover, the prohibitive costs of such triple therapies will limit their use in patients in developing countries where most of the $\mathrm{HCV}$ infection exists. Understanding the host and viral factors associated with viral clearance is necessary for individualizing therapy to maximize sustained virologic response rates, prevent progression to liver disease, and increase the overall benefits of therapy with respect to its costs. Genome wide studies have shown significant associations between a set of polymorphisms in the region of the interleukin-28B (IL28B) gene and natural clearance of HCV infection or after PEGylated interferon-alpha and ribavirin treatment with and without direct antiviral agents. This paper synthesizes the recent advances in the pharmacogenetics of HCV infection in the era of triple therapies.
\end{abstract}

Keywords: hepatitis C virus, interleukin-28B polymorphisms, PEGylated interferon and ribavirin, direct-acting antiviral agents, pharmacogenetics, rational therapeutics

\section{Introduction}

The World Health Organization estimates that 170-200 million people worldwide, ie, $3 \%$ of the world's population, is infected with hepatitis $\mathrm{C}$ virus (HCV). ${ }^{1}$ In the USA, nearly $2 \%$ of the population is infected. ${ }^{2}$ In northern parts of Europe, the prevalence is less than $0.1 \%$, but increases to more than $1 \%$ in the south. ${ }^{3}$ The prevalence of HCV infection is greater in Africa and Asia, with infection rates exceeding 5\%. ${ }^{1,4}$ Egypt has the highest prevalence of hepatitis $\mathrm{C}$ in the world, with $15 \%$ of the population affected. ${ }^{5,6}$

Acute HCV infection is mostly asymptomatic and rarely recognized clinically. Spontaneous viral clearance (SVC) occurs in approximately $25 \%$ of patients. ${ }^{7}$ The striking feature of $\mathrm{HCV}$ infection is its tendency to persist and develop
Correspondence: Sanaa M Kamal Department of Medicine, Division of Hepatology, Gastroenterology and Tropical Medicine, Ain Shams Faculty of Medicine, 22 Al Ahram Street, Roxy, Heliopolis, I I34 I Cairo, Egypt

Tel +20 I 0 I 474350

Fax +20235365799

Email sanaakamal@ainshamsmedicine.net 
into chronic hepatitis. Some patients with chronic $\mathrm{HCV}$ are at increased risk of developing liver cirrhosis and hepatocellular carcinoma and will eventually develop serious sequelae. ${ }^{8,9}$

The treatment available for HCV has changed significantly over recent decades, with the standard of care shifting from conventional interferon (IFN) monotherapy to IFN and ribavirin combination therapy to PEGylated IFN (PEGIFN) with ribavirin. IFN $\alpha$ has potent antiviral activity due to its ability to induce IFN-stimulated genes that encode proteins which inhibit various stages of viral replication. ${ }^{10}$ In addition, IFN $\alpha$ has an immunomodulatory effect, interacting with both the adaptive and innate immune response of the host. IFN $\alpha$ promotes T-helper (Th) cell differentiation of T-lymphocytes over Th2 cells, leading to increased production of interleukin (IL)-2 and IFN $\gamma$. In addition, IFN $\alpha$ exerts an anti-inflammatory effect by inhibiting the synthesis of various cytokines, including tumor necrosis factor-alpha and IL-1. ${ }^{11}$ IFN $\alpha$ binds with its specific receptor on the surface of target cells, activating an intracellular signaling cascade, which causes the induction of IFN-stimulated genes (ISGs), establishing a nonvirus-specific antiviral state inside the cell. ${ }^{12,13}$ Janus kinase/signal transducers and activators of transcription pathway are the principal signaling mechanisms used by IFNo. ${ }^{14}$

Cytoplasmic proteins with the activity of tyrosine kinase associated with IFN $\alpha$ receptor, activated Jak1, and tyrosine kinase 2 are activated by dimerization of the receptors. Activated Jak1 and tyrosine kinase 2 phosphorylate STAT1 and STAT2, respectively. Phosphorylated STAT1 and STAT2 bond with protein $\mathrm{p} 48$, forming IFN-stimulated gene factor 3 , that translocates into the nucleus and binds with IFN-stimulated regulatory element in the sequences that promote a variety of genes inducible by IFN $\alpha$, including antiviral proteins such as $2^{\prime} 5^{\prime}$-oligoadenylate synthetase, protein kinase RNA, and Mx protein. ${ }^{12-15}$

The mechanisms of action of ribavirin are not fully understood. It has been postulated that ribavirin acts via direct inhibition of HCV replication, inhibition of the host inosine monophosphate dehydrogenase enzyme, induction of mutagenesis to drive a rapidly replicating virus beyond the threshold to error catastrophe, and immunomodulation by inducing a Th1 immune response. ${ }^{16}$

The percentages of patients achieving a sustained virologic response (SVR), defined as undetectable $\mathrm{HCV}$ RNA 24 weeks after completion of treatment, improved significantly with advances in the therapeutic regimens available. However, SVR rates are still below target, especially for the difficult to treat $\mathrm{HCV}$ genotypes 1 and 4 . Management of relapsers and nonresponders remains a challenging and controversial issue. In addition, all of the aforementioned IFN-based regimens have moderate to severe side effects, including hematologic adverse events (neutropenia, thrombocytopenia), fatigue, irritability, fever, myalgia, arthralgia, inflammation at the injection site, and cardiac dysrhythmia, that negatively influence the tolerability and adherence of patients with therapy. The prohibitive cost of treatment is another problem facing patients in developing countries where most cases of chronic HCV are clustered.

All of the above factors have driven a need to develop new treatments that are safer and more effective. Recently, a number of direct-acting antiviral agents (DAAs) have been developed for use with PEG-IFN/ribavirin as triple therapies or IFN-free therapy. The efficacy of such therapies varies according to genotype and host characteristics. This paper provides an overview of advances made in understanding the pharmacogenetics of HCV infection during the transition from IFN-based therapies to triple therapies and IFN-free regimens.

\section{Acute hepatitis C: an emerging field of pharmacogenetics}

The percentage of patients with clinically diagnosed acute $\mathrm{HCV}$ infection is low, since $70 \%-80 \%$ of acute $\mathrm{HCV}$ infections are asymptomatic. ${ }^{7-10}$ To date, there are no reliable criteria to predict patients in whom HCV infection will spontaneously resolve and those who will develop chronic infection. The acute phase of the infection is the period during which PEG-IFN $\alpha$ monotherapy is associated with high response rates of up to $80 \%-90 \% .{ }^{17-24}$ It is generally acceptable to treat patients with acute $\mathrm{HCV}$ who fail to clear viremia 3 months after infection with 12-24-week courses of PEGIFN $\alpha$ monotherapy. ${ }^{17-19}$ SVR rates decrease markedly when treatment is not started until the chronic phase of infection. ${ }^{19}$ Being able to predict which patients with acute $\mathrm{HCV}$ infection are likely not to clear HCV spontaneously is critical for the success of acute HCV therapy, because it will enable physicians to initiate therapy early to eradicate $\mathrm{HCV}$, prevent chronic evolution of the disease, and avoid the adverse events of long-term combination PEG-IFN and ribavirin therapy. Thus, an indepth understanding of the molecular mechanisms and genetic determinants of spontaneous resolution will help to identify reliable biomarkers for acute $\mathrm{HCV}$ clearance and determine new targets to personalize treatment strategies for acute HCV infection. 


\section{Determinants of spontaneous resolution of acute $\mathrm{HCV}$}

Some clinical features have been associated with SVC in patients with acute HCV. Patients younger than 40 years of age, children, women, and patients with symptomatic disease, particularly jaundice, are more likely to undergo spontaneous resolution. ${ }^{10,17,24-28}$

\section{Viral factors}

Some virologic factors have been associated with spontaneous resolution. Farci et $\mathrm{al}^{29}$ showed that acute resolving hepatitis was associated with HCV homogeneity, whereas progressing hepatitis was associated with genetic diversity, presumably reflecting greater immune pressure during acute spontaneous clearance. Individuals coinfected with $\mathrm{HCV}$ and human immunodeficiency virus (HIV) ${ }^{30,31}$ or with $\mathrm{HCV}$ and Schistosoma mansoni are far less likely to clear HCV spontaneously. ${ }^{32-35}$ Additionally, patients with compromised immune systems, such as organ transplant recipients, frequently progress to chronic infection. ${ }^{36}$

\section{Immunologic factors}

Early events in the interaction between HCV and the immune system likely determine the outcome of infection. Clearance of $\mathrm{HCV}$ is associated with the development of robust and multispecific $\mathrm{CD}^{+}$and $\mathrm{CD} 8^{+}$T-cell responses in the blood and liver that can persist for years after recovery from the acute disease. ${ }^{29}$ In contrast, individuals who progress to chronic infection fail to mount such a response or may have inadequate production of the cytokines essential for control of viral replication. Incomplete control of viral replication by $\mathrm{CD}^{+} \mathrm{T}$-cells in the absence of sufficient memory $\mathrm{CD}^{+}{ }^{+} \mathrm{T}$-cells leads to viral persistence and emergence of cytotoxic T-lymphocyte escape mutants. ${ }^{37-40}$ However, it is still not clear why so few individuals mount a successful $\mathrm{HCV}$-specific immune response capable of eradicating the infection and the majority fail to do so.

\section{Genetic factors}

Genetic studies have shown that individual genetic make-up is an important host determinant for outcome and progression of acute HCV infection. One study showed that genes encoding the inhibitory natural killer cell receptor KIR2DL3 and its human leukocyte antigen $\mathrm{C}$ group 1 ( $H L A-C 1)$ ligand influenced the likelihood of spontaneous resolution of $\mathrm{HCV}$ infection, suggesting that inhibitory natural killer cell interactions are critical for antiviral immunity. ${ }^{41} \mathrm{IL}-18$ is a pivotal mediator of the Th1/Th2-driven immune response.
IL-18 promoter polymorphisms $(-607 \mathrm{C} / \mathrm{A}$ and $-137 \mathrm{G} / \mathrm{C})$ were found to be associated with SVC.42

\section{IL28B polymorphism and outcome of acute $\mathrm{HCV}$}

Genome wide association studies have added new insights into the pathophysiology and pharmacology of HCV infection. Genome wide association studies have the advantage of focusing resources on a manageable number of genes and polymorphisms that are likely to be important. The strength of genome-wide screening is its ability to reveal not only genes expected to play a significant role, but also genes that are not involved in the pathogenesis of the disease. Polymorphisms of genes involved in innate immunity as well as those of genes encoding cytokines and other immunologic mediators may explain spontaneous recovery from acute $\mathrm{HCV}$ and influence the strength and nature of immune defense.

IL28B is located on chromosome 19 and encodes IFNlambda (IFN $\lambda$ ), a newly described family of type III IFN that is distantly related to type I IFNs and IL-10. IFN $\lambda$ includes IFN $\lambda$ 1, 2 and 3, also known as IL29, IL28A, and IL28B. ${ }^{43}$ Several studies ${ }^{24,44-48}$ have shown that single nucleotide polymorphisms (SNPs) in the $I L 28 B$ region may play a critical role in determining the outcome of acute infection (clearance versus persistence). A strong association has been found between polymorphisms in or near $I L 28 B$, the pathogenesis of $\mathrm{HCV}$, and outcome of acute $\mathrm{HCV}$ infection. Ge et $\mathrm{al}^{47}$ observed that the $\mathrm{C}$ allele occurred more frequently in patients with spontaneous clearance. Further, Thomas et $\mathrm{a}^{44}$ showed that the SNP rs12979860 upstream of IL28B and the $\mathrm{C} / \mathrm{C}$ genotype were associated with spontaneous clearance of $\mathrm{HCV}$, and this finding was confirmed by recent studies in patients with acute $\mathrm{HCV}^{37,41}$ Interestingly, jaundice during acute infection was more common in patients with the $\mathrm{C} / \mathrm{C}$ genotype. ${ }^{24,46} \mathrm{The} \mathrm{T} / \mathrm{T}$ genotype occurred more often in people of African descent, had an intermediate frequency among Europeans, and a lower frequency among Asians, a finding that partly explains the ethnic differences seen in spontaneous acute HCV recovery rates across different ethnic groups. The risk variant of the $I L 28 B$ gene may produce IFN $\lambda$ that may affect the adaptive immune response and IFN-stimulated genes. ${ }^{44}$

In a recent study ${ }^{24}$ of a well characterized cohort of acute HCV patients, we showed that a decrease in alanine aminotransferase within 4 weeks (odds ratio [OR] 6.83; $P<0.0001$ ), jaundice (OR 3.54; $P=0.001$ ), female sex (OR 2.39; $P=0.007)$, and a $>2.5 \log _{10}$ decrease in HCV-RNA 
within 8 weeks (OR 2.48; $P=0.016$ ) were independently associated with spontaneous clearance. $I L 28 B$ CC was also associated with a multispecific T-cell response $\left(r^{2}=0.0 .835\right.$; $P<0.001)$. These findings have important implications for predicting the outcome of $\mathrm{HCV}$ exposure and acute infection and identifying patients likely to benefit from therapy.

Taken together, genetic variations play an important role in spontaneous resolution or persistence of HCV infection. Given the benefits of early treatment of acute HCV and the critical timing of initiation of therapy, ${ }^{11-16,25}$ integrating genetic markers such as $I L 28 B$ genotyping into the matrix of diagnostics for acute $\mathrm{HCV}$ will help to target therapy to individuals with a high likelihood of developing chronic $\mathrm{HCV}$ infection and eradicate the virus with a short regimen of PEG-IFN $\alpha$ monotherapy.

\section{Chronic HCV therapy: from IFN- based therapies to direct-acting antiviral agents}

Despite extensive efforts, there is still no vaccine available for HCV. Thus, control of HCV infection depends on preventive measures, early detection, and treatment of acute or chronic infection.

\section{PEG-IFN and ribavirin therapy}

The current standard of care is PEG-IFN $\alpha-2 b$ and ribavirinbased therapy. The primary goal of antiviral therapy in patients with chronic hepatitis $\mathrm{C}$ is achieving an SVR, defined as undetectable serum HCV-RNA by a sensitive molecular assay 24 weeks after completion of therapy. Although the standard of care improves SVR rates in HCV genotypes 2 and 3, the response is still suboptimal in genotypes 1 and 4 and in particular patient populations. Furthermore, antiviral therapy is associated with several adverse events and high costs that represent a huge burden for developing countries. Thus, individualization and personalization of treatment with identification of factors associated with SVR are critical to maximize efficacy and spare patients preventable adverse events and expense. A number of host and viral factors influence SVR rates in patients with chronic HCV. An SVR is more likely in young individuals, females, patients infected with genotypes 2 or 3, and those with low pretreatment HCV-RNA levels, no or minimal liver fibrosis, and adequate adherence to therapy. ${ }^{49-60}$ Infection with HCV genotype 1 or 4, high baseline HCV RNA levels ( $>800,000 \mathrm{IU} / \mathrm{mL}$ ), steatosis, insulin resistance, and coinfection with HIV are associated with low response rates. ${ }^{49-52}$
In an effort to improve rates of sustained response to therapy in patients with chronic HCV infection, various strategies have been adopted to tailor the treatment duration according to the on-treatment response. A number of studies have investigated shortened courses of treatment to minimize adverse effects and costs without compromising efficacy. In patients with chronic HCV genotype 2 or 3 who had undetectable HCV-RNA at 4 weeks of therapy (rapid virologic response), a shorter PEG-IFN $\alpha$ and ribavirin regimen (12-24 weeks) was associated with SVR rates similar to those achieved with 48 weeks of treatment. ${ }^{53,54}$ Clinical trials have also demonstrated the efficacy of 24 weeks of combination PEG-IFN and ribavirin therapy in patients with chronic hepatitis genotype 1 and 4, who achieved a rapid virologic response defined as undetectable viremia after 4 weeks of treatment. ${ }^{50,51,58-60}$

\section{Direct-acting antiviral agents}

DAAs were developed to improve SVR rates, reduce adverse events, and improve adherence to therapy in HCV patients. These drugs target the different stages of virus development and replication. Production of DAAs was heralded by extensive research to clarify the viral life cycle of $\mathrm{HCV}$ in an attempt to develop novel drugs that terminate the cycle before its completion, thereby inhibiting development and replication of the virus. Several clinical trials investigating DAAs have yielded encouraging results that provide hope for patients with chronic HCV. DAAs can be classified into two main groups, ie, first-generation and second-generation protease inhibitors.

\section{First-generation protease inhibitors}

The most important DAAs belong to the class of protease inhibitors targeting NS3/4 protease. These first-generation protease inhibitors have been assessed in large clinical trials. Boceprevir and telaprevir are the first-generation oral protease inhibitors. These agents have been approved by regulatory authorities and are currently used in clinical practice. Boceprevir acts as a noncovalent inhibitor of cytochrome P450 A4 and P-glycoprotein. Addition of boceprevir or telaprevir to PEG-IFN and ribavirin significantly increased SVR rates and shortened the treatment duration in naïve, relapsing, and partially responding patients..$^{61,62}$ The PEGIFN/ribavirin/telaprevir regimen was associated with an SVR of $75 \%$ in patients who received the combination for 12 weeks. ${ }^{61}$ The SPRINT-2 trial (ClinicalTrials.gov registry number NCT00705432), which included more than 1,000 previously untreated adults with HCV genotype 1 infection, 
reported SVR rates of $63 \%$ in the response-guided boceprevir group and $66 \%$ in the fixed-duration boceprevir group, compared with $38 \%$ in the PEG-IFN/ribavirin group. ${ }^{62}$

Consequently, current practice guidelines recommend a triple therapy regimen combining PEG-IFN, ribavirin, and telaprevir or boceprevir. In the case of telaprevir, triple therapy is administered for the first 12 weeks followed by a period of dual PEG-IFN/ribavirin therapy for a total of 24-48 weeks, depending on response. In the case of boceprevir, dual PEGIFN/ribavirin therapy is given for the first 4 weeks followed by a period of 44 weeks of triple therapy. ${ }^{63}$ However, triple therapy with boceprevir or telaprevir has some drawbacks, including drug-drug interactions and viral resistance.

Although triple therapy has improved SVR rates, this regimen increases adverse events such as rash and moderate to severe anemia to an extent that might require reduction of the ribavirin dose. Patient adherence to and tolerability of triple therapy including boceprevir or telaprevir is a challenging issue because these two DAAs should be given three times daily with food. Boceprevir and telaprevir are only effective against genotype 1 , with recent studies showing that these protease inhibitors have no antiviral activity against genotype 2, 3, or 4. Further, triple therapy is ineffective in patients who have not responded to previous dual PEG-IFN/ribavirin therapy. From an economic perspective, triple therapy has dramatically increased the costs of HCV treatment, which are originally prohibitive.

\section{Second-generation protease inhibitors}

Second-generation protease inhibitors, such as simeprevir, asunaprevir, and danoprevir, are currently being evaluated in an effort to overcome the limited efficacy of the firstgeneration protease inhibitors in $\mathrm{HCV}$ genotypes 2, 3, and 4 and to minimize their adverse events. ${ }^{64}$

The PILLAR (PIvotaL Lymphoma triAls of RAD001) trial $^{65}$ investigated the efficacy and safety of two different simeprevir doses administered once daily with PEGIFN $\alpha-2 \mathrm{a}$ and ribavirin in treatment-naïve patients with HCV genotype 1 infection. According to response-guided therapy criteria, $79.2 \%-86.1 \%$ of simeprevir-treated patients completed treatment by week $24 ; 85.2 \%-95.6 \%$ of these patients subsequently achieved an SVR. The safety profile of triple therapy including simeprevir was found to be comparable with that of combination PEG-IFN/ribavirin therapy.

Triple therapy comprising danoprevir, PEG-IFNo-2a, and ribavirin was assessed in a clinical trial conducted in patients with chronic HCV genotype 1. SVR rates were higher in patients given danoprevir $300 \mathrm{mg}$ (68\%), $600 \mathrm{mg}$
(85\%), and $900 \mathrm{mg}(76 \%)$ than in those on placebo (42\%). Seventy-nine percent of patients given danoprevir $600 \mathrm{mg}$ had a rapid virologic response; among these, 96\% had an SVR. Serious adverse events were reported in $7 \%-8 \%$ of patients given danoprevir and four patients given danoprevir (one patient in the $600 \mathrm{mg}$ group and three in the $900 \mathrm{mg}$ group) had reversible grade 4 increases in alanine aminotransferase, which led to early discontinuation of the $900 \mathrm{mg}$ arm of the study. ${ }^{66}$

In the DAUPHINE trial (ClinicalTrials.gov registry number NCT0122094), treatment-naïve patients with HCV genotype 1 or 4 were randomized to receive twice-daily danoprevir/ribavirin 200/100 mg, 100/100 mg, or 50/100 mg plus PEG-IFN and ribavirin for 24 weeks; twice-daily danoprevir/ ribavirin 100/100 mg plus PEG-IFN and ribavirin for 12 or 24 weeks; or PEG-IFN and ribavirin alone for 48 weeks. Patients in the response-guided therapy arm with an extended rapid virologic response ( $\mathrm{HCV}$ RNA $<15 \mathrm{IU} / \mathrm{mL}$ during weeks 2-10) stopped all therapy at week 12; patients without an extended rapid virologic response continued all treatment to week 24. The combination of danoprevir/ribavirin plus PEG-IFN and ribavirin was an effective and safe therapy in treatment-naïve patients with $\mathrm{HCV}$ genotype 1 or 4 infection. ${ }^{67}$

\section{Polymerase inhibitors}

Polymerase inhibitors are another class of DAAs that have recently shown much potential. These drugs bind to NS5B polymerase to halt replication of the virus. Nucleoside analog inhibitors, a category of polymerase inhibitors, are incorporated into the HCV RNA chain leading to direct chain termination. They are potentially active against all HCV genotypes, and viral resistance to these agents is low and less frequent than with non-nucleoside inhibitors, the other class of polymerase inhibitors that bind to several discrete sites outside of the polymerase active center, causing a conformational protein change. ${ }^{6}$

Sofosbuvir is a nucleoside analog inhibitor and has recently been approved by the US Food and Drug Administration. It has a high barrier to viral resistance, and no virologic breakthrough has been recorded so far. One major feature of sofosbuvir is its pan-genotypic antiviral effect. It is given orally once a day and does not require concurrent or prior food intake. ${ }^{6}{ }^{8}$ Several treatment strategies involving sofosbuvir have been considered and tested. ${ }^{69,70}$ The first strategy is to add sofosbuvir to PEG-IFN and ribavirin. One study ${ }^{69}$ has assessed the safety and efficacy of sofosbuvir in combination with PEG-IFN and ribavirin in 316 noncirrhotic 
treatment-naïve patients with $\mathrm{HCV}$ genotype-1 (52 to cohort A, 109 to cohort B, 155 to cohort C, and eleven with HCV genotype 4 and five with genotype 6 to cohort D). In patients with $\mathrm{HCV}$ genotype 1, SVR24 was achieved by 46 patients $(89 \%, 95 \%$ confidence interval [CI] 77-96) in cohort A, 97 patients (89\%, CI 82-94) in cohort B, and 135 (87\%, CI 81-92) in cohort C. There was no difference in the proportion of patients achieving SVR24 in cohort A and cohort B $(P=0.94)$ or cohort $\mathrm{C}(P=0.78)$. Nine $(82 \%)$ of the eleven patients with genotype 4 and all five with genotype 6 achieved SVR24.

\section{Interferon-free sofosbuvir regimen}

Another strategy is to use sofosbuvir and ribavirin without PEG-IFN. Gane et al ${ }^{71}$ evaluated an all-oral regimen comprising the nucleotide polymerase inhibitor sofosbuvir with the NS5A inhibitor ledipasvir or the NS5B non-nucleoside inhibitor GS-9669 in 113 patients with genotype $1 \mathrm{HCV}$ infection. Sofosbuvir (400 mg once daily) and ledipasvir (90 mg once daily) plus ribavirin were given for 12 weeks to treatment-naïve patients $(n=25)$ and those who did not respond to previous therapy (prior null responders, $n=9$ ). Sofosbuvir and GS-9669 (500 mg once daily) plus ribavirin were given for 12 weeks to treatment-naïve patients $(n=25)$ and prior null responders $(\mathrm{n}=10)$. Additionally, prior null responders with cirrhosis were randomly assigned to receive a fixed-dose combination of sofosbuvir and ledipasvir, with ribavirin $(n=9)$ or without ribavirin $(n=10)$. Finally, a group of treatment-naïve patients received sofosbuvir, ledipasvir, and ribavirin for 6 weeks $(n=25)$. SVR12 was achieved by $25 / 25(100 \%)$ treatment-naïve patients receiving sofosbuvir, ledipasvir, and ribavirin and 23/25 (92\%) of those receiving sofosbuvir, GS-9669, and ribavirin. Of the 25 treatment-naïve patients receiving 6 weeks of sofosbuvir, ledipasvir, and ribavirin, 17 (68\%) achieved SVR12. All noncirrhotic prior null responders receiving 12 weeks of sofosbuvir along with another direct-acting antiviral agent plus ribavirin achieved an SVR12, ie, 9/9 (100\%) of those receiving sofosbuvir, ledipasvir, and ribavirin and 10/10 (100\%) of those receiving sofosbuvir, GS-9669, and ribavirin. Among cirrhotic prior null responders, SVR12 was achieved by nine (100\%) of those receiving sofosbuvir, ledipasvir, and ribavirin, and seven $(70 \%)$ of those receiving sofosbuvir and ledipasvir without ribavirin. $^{71}$

An open-label study ${ }^{72}$ randomized 100 noncirrhotic treatment-naïve patients to receive sofosbuvir plus ledipasvir for 8 weeks (group 1), sofosbuvir plus ledipasvir and ribavirin for 8 weeks (group 2), or sofosbuvir plus ledipasvir for 12 weeks (group 3). This trial showed that the fixed-dose sofosbuvir-ledipasvir combination alone or with ribavirin has the potential to cure most patients with HCV genotype 1, irrespective of treatment history or the presence of compensated cirrhosis.

\section{Pharmacogenomics for individualization of HCV therapies}

Pharmacogenomics could play a crucial role in optimizing $\mathrm{HCV}$ therapy by taking into account ethnic variations in response to therapy, ${ }^{73}$ identifying variations in treatment response, elucidating the molecular mechanisms of current and future therapies, and development of innovative genetic tools that will enable physicians to individualize drug therapy, adjust dosages, and reduce the likelihood of adverse effects and therapeutic costs.

\section{IL28B polymorphism and outcome of chronic HCV therapy}

The link between $I L 28 B$ and the outcome of HCV reported by several groups has revolutionized our understanding of host determinants of treatment response. Several independent studies ${ }^{74-94}$ have demonstrated a strong association between polymorphisms in or near the IL28B and SVR to IFN-based therapy or triple PEG-IFN, ribavirin, and DAA therapies (Table 1). These findings have increased our understanding of the genetic basis of response to therapy.

Ge et $\mathrm{al}^{47}$ demonstrated that patients with the $\mathrm{C} / \mathrm{C}$ genotype have a greater likelihood of HCV clearance than those with the $\mathrm{C} / \mathrm{T}$ and $\mathrm{T} / \mathrm{T}$ genotypes. The $\mathrm{C}$ allele is more frequent in individuals of European ancestry than in those of African ancestry, suggesting that the prevalence of $\mathrm{C} / \mathrm{C}$ may account for ethnic differences in $\mathrm{HCV}$ clearance rates.

Tanaka et $\mathrm{al}^{74}$ and Suppiah et $\mathrm{al}^{75}$ reported that several relevant $I L 28 B$ polymorphisms on chromosome 19 were associated with the outcome of IFN therapy. In Japanese patients, polymorphism in the SNP rs8099917 was a better predictor of response to PEG-IFNo/ribavirin therapy than other SNPs associated with $I L 28 B .{ }^{76}$ Darling et $\mathrm{al}^{77}$ and Lagging et $\mathrm{al}^{78}$ demonstrated that quantitation of pretreatment serum IFN $\gamma$ inducible protein-10 improves the predictive value of an IL28B gene polymorphism for response to HCV treatment.

Two studies ${ }^{79,80}$ have investigated the intrahepatic expression of ISGs and genetic variation in IL28B (rs8099917) in Japanese and North American patients with chronic hepatitis $\mathrm{C}$ who received combination PEG-IFN and ribavirin therapy. Gene expression profiling of the liver showed that a high proportion of nonresponders had upregulated ISG. Expression of 


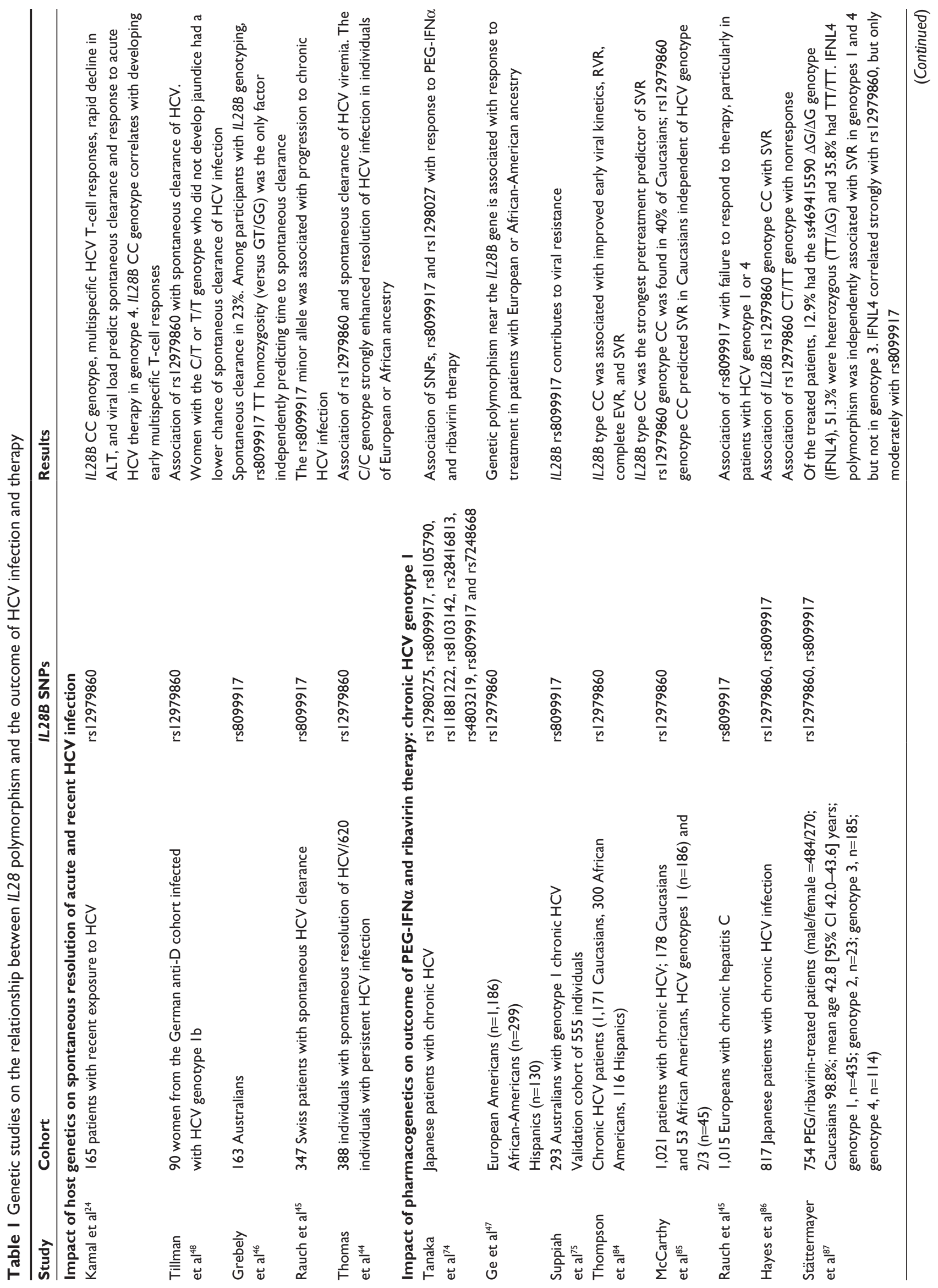




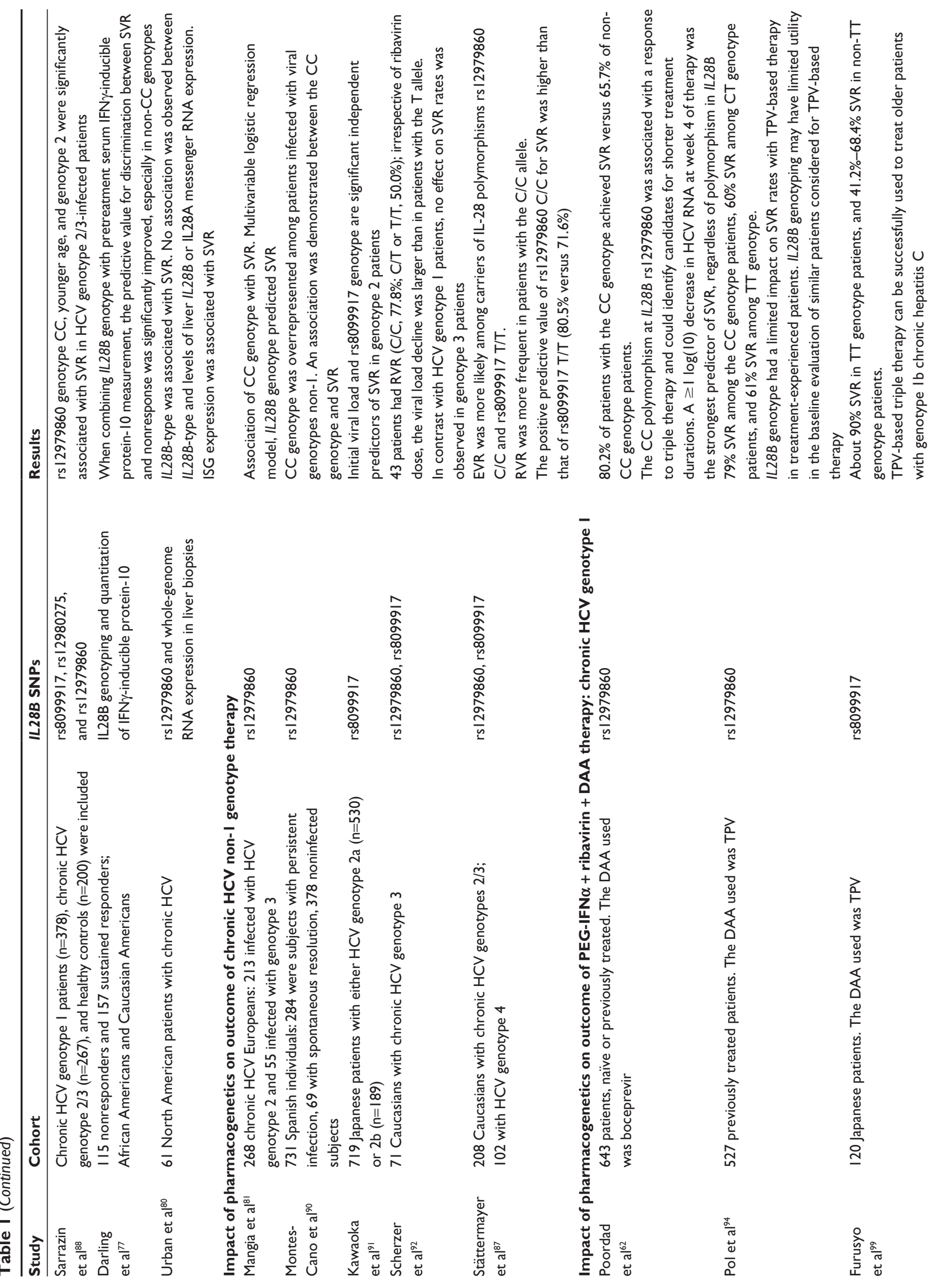



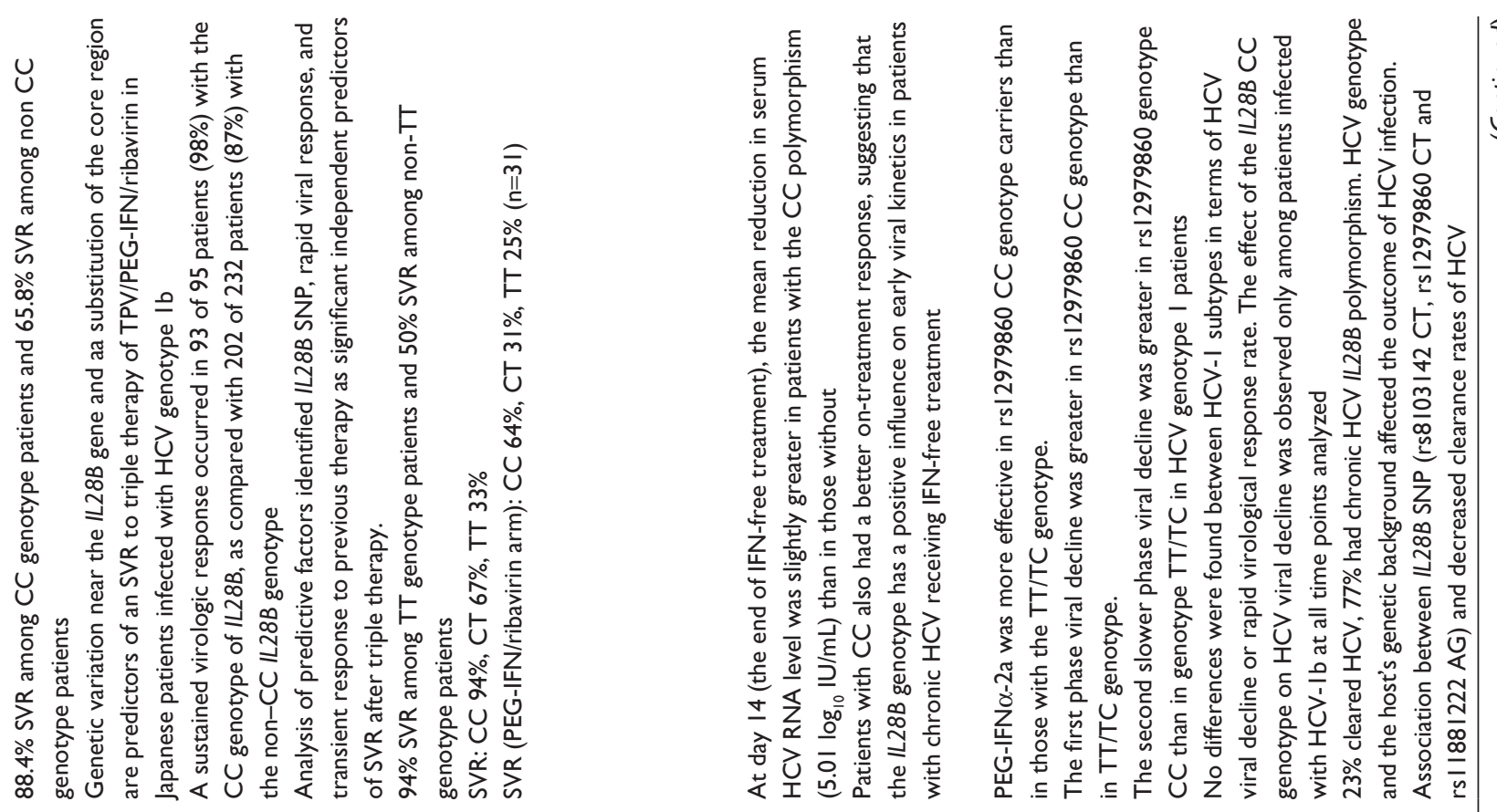

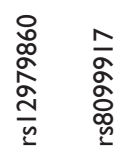

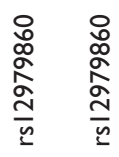

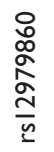

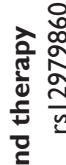

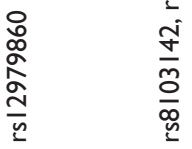

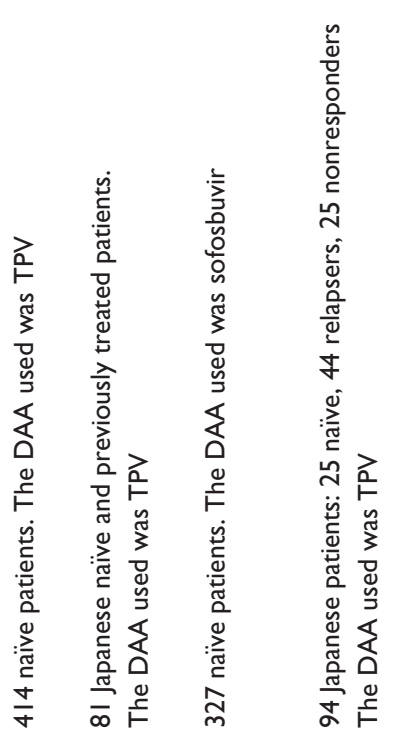
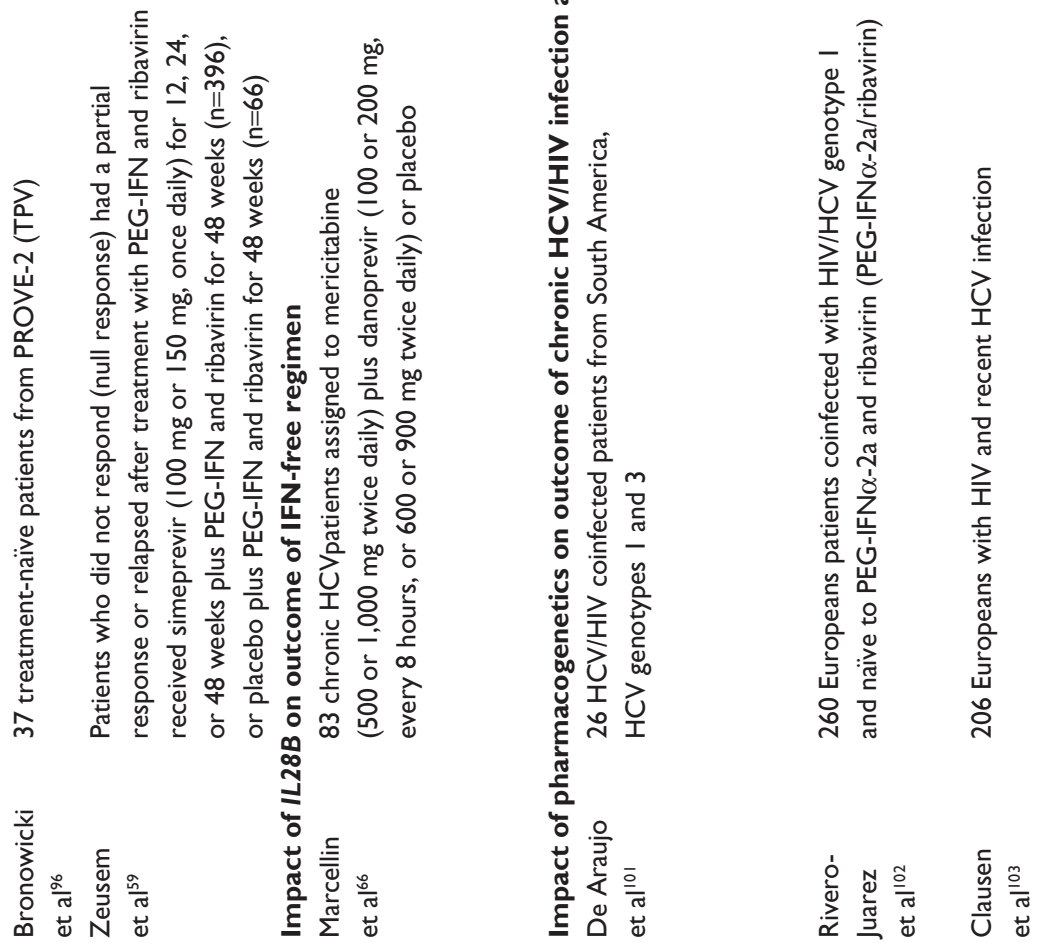

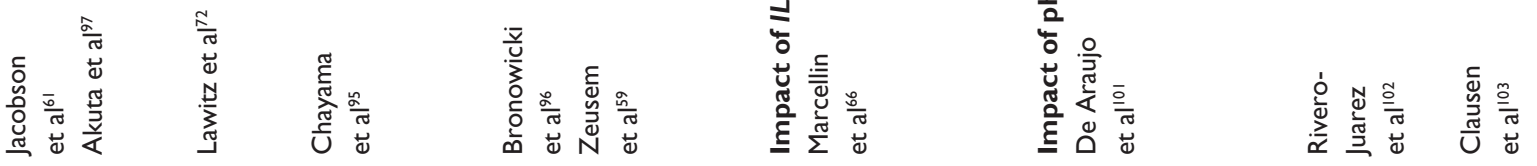




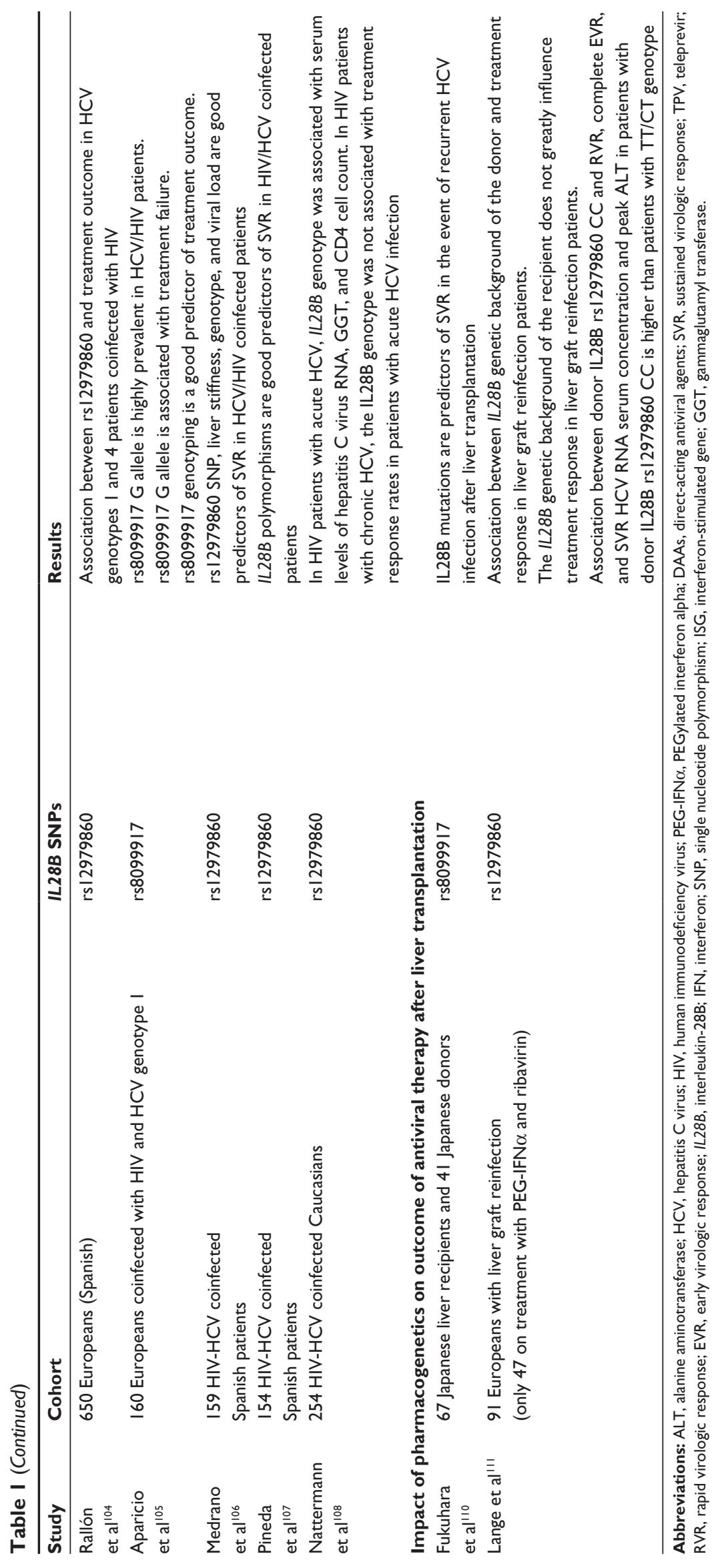


hepatic ISG was strongly associated with treatment response and genetic variation of IL28B. Multivariate logistic regression analysis showed that ISG, fibrosis stage (F1 or F2), and mutation in the interferon sensitivity-determining region $(\geq 2)$ were strongly associated with the viral response. Urban et $\mathrm{al}^{80}$ found no association between $I L 28 B$ type and levels of liver $I L 28 B$ or $I L 28 A$ messenger RNA expression.

\section{IL28B polymorphisms and response of nongenotype I HCV infections to treatment}

IL28B SNP rs12979860 was significantly associated with SVR to PEG-IFN/ribavirin therapy in chronic HCV genotype 2/3. ${ }^{81}$ A study ${ }^{82}$ has investigated the association of IL28B polymorphism with response to treatment or liver disease severity in a cohort of patients with HCV genotype 4. Carriers of the C/C allele of the IL28B gene SNP rs 12979860 achieved significantly higher SVR rates $(81.8 \%)$ when compared with $46.5 \%$ and $29.4 \%$ for genotypes CT and TT, respectively $(P=0.0008)$. No significant relationship was found between rs12979860 and severity of disease. Another study ${ }^{83}$ showed that the rs 12979860 , rs8099917, and rs11881222 IL28B SNPs were the strongest predictors of a response to $\mathrm{PEG}-\mathrm{IFN}$ and ribavirin in patients with chronic HCV genotype 4.

\section{Genetic polymorphism in IL28B and viral kinetics during therapy}

Rapid and early virologic responses are important ontreatment predictors of response to PEG-IFN and ribavirin. Moreover, patients who achieve a rapid virologic response can be treated with 24 weeks rather than 48 weeks of standard therapy. In Caucasians, the CC IL28B type was associated with improved early viral kinetics and a greater likelihood of a rapid virologic response, complete early virologic response, and SVR compared with the CT and TT genotypes. ${ }^{84}$ A similar relationship was seen in African Americans and Hispanics. In a multivariable regression model, the CC IL28B type was the strongest pretreatment predictor of SVR (odds ratio 5.2; 95\% CI 4.1-6.7). However, rapid virologic response was a strong predictor of SVR regardless of IL28B type. An early virologic response to $\mathrm{PEG}-\mathrm{IFN}$ and ribavirin is more likely among carriers of rs $12979860 \mathrm{C} / \mathrm{C}$ and rs8099917 T/T, which might underlie their high rates of SVR.

Thus, IL28B polymorphisms did not influence SVR in easy-to-treat patients, such as those with genotype $2 / 3$, rapid virologic responders, and those with acute hepatitis $\mathrm{C}$. While the genetic fingerprint for progression of fibrosis remains elusive, IL28B polymorphism predicts SVC and SVR. However, nearly half of the patients achieving an SVR did not have a favorable genotype. Further genetic signals need to be identified to complete the puzzle of factors influencing hepatitis $\mathrm{C}$.

\section{IL28B polymorphisms and DAAs}

Several studies have investigated whether IL28B polymorphisms have an impact on response rates to triple PEG-IFN, ribavirin, and DAA therapy.

\section{Boceprevir}

The SPRINT- $2^{62}$ trial tested the efficacy of triple PEG-IFN, ribavirin, and boceprevir therapy in treatment-naïve patients with HCV genotype 1 and investigated the impact of $I L 28 B$ polymorphisms on response rates. The SVR rate in patients with the IL28B CC genotype and treated with dual PEG IFN/ ribavirin therapy was $78 \%$, and was very similar to the SVR rates observed in patients with the $\mathrm{CC}$ genotype receiving triple therapy $(80 \%)$. However, a dramatic increase was seen in patients with the TT genotype, whereby SVR rates increased significantly from $27 \%$ in patients treated with combination PEG IFN/ribavirin therapy to $59 \%$ in patients receiving triple therapy; a statistically significant increase in SVR rate was also seen in those with the CT genotype ( $28 \%$ versus $71 \%$, respectively). In other words, patients with nonfavorable $I L 28 B$ genotypes were those who experienced significant improvement in SVR rates with the addition of boceprevir.

The RESPOND-2 trial (ClinicalTrials.gov registry number, NCT00708500) investigated the response of 106 treatment-experienced patients to triple therapy with boceprevir. A significant improvement in SVR rates was observed for all $I L 28 B$ genotypes when boceprevir was added to PEG-IFN/ribavirin therapy. The SVR rate increased from $46 \%$ to $77 \%$ in those with the CC genotype, from $17 \%$ to $73 \%$ in those with the CT genotype, and from $50 \%$ to $72 \%$ in those with the TT genotype. ${ }^{62}$

\section{Telaprevir}

A trial comparing the efficacy of triple PEG-IFN/ribavirin/ telaprevir therapy with that of combination PEG-IFN/ribavirin therapy showed that SVR rates increased significantly in carriers of the CC genotype from $64 \%$ on dual therapy to $90 \%$ on triple therapy. ${ }^{95}$ An improvement in SVR rates was also observed in patients with the CT genotype (from 25\% to $71 \%$ ) and the TT genotype (from $23 \%$ to $73 \%$ ). Similarly, 
the PROVE-2 trial ${ }^{96}$ demonstrated enhanced SVR rates in treatment-naïve patients with any IL28B genotype, including the TT genotype.

The REALIZE trial (ClinicalTrials.gov registry number NCT00703118) ${ }^{97}$ showed that triple PEG-IFN/ribavirin/telaprevir therapy in treatment-experienced patients achieved a significant increase in SVR rates over the standard of care in all $I L 28 B$ genotypes (from $29 \%$ to $79 \%$ for CC, $16 \%$ to $60 \%$ for CT, and $13 \%$ to $61 \%$ for TT). A metaanalysis of five studies including 1,641 patients treated with a triple regimen including telaprevir in four studies and boceprevir in the remaining study demonstrated that addition of a DAA to the PEG-IFN and ribavirin standard of care significantly improved the SVR rate across all IL28B genotypes. In addition, patients with the CC genotype had higher SVR rates than those with the CT or TT genotype, regardless of whether patients were naïve, nonresponders, or relapsers. ${ }^{98}$

Furusyo et al $^{99}$ focused on the impact of the rs8099917 SNP on the response to triple therapy (with telaprevir being the DAA), and concluded that patients with the TT allele had significantly higher SVR rates than those with the TG or GG allele. All these patients had HCV genotype 1 .

\section{Simeprevir}

The impact of $I L 28 B$ polymorphism on response to triple therapy with simeprevir among treatment-naïve patients was investigated in a subset of patients enrolled in the PILLAR trial, ${ }^{65}$ which focused on the rs12979860 SNP. Addition of simeprevir resulted in significantly improved SVR rates in all $I L 28 B$ genotypes when compared with combination PEG-IFN/ribavirin therapy. SVR rates improved from $18 \%$ to $88 \%$ in those with the CC genotype, from $31 \%$ to $74 \%$ in those with the CT genotype, and from $14 \%$ to $61 \%$ in those with the TT genotype. Among patients with non-CC genotypes, SVR24 rates were generally higher for patients treated with simeprevir $75 \mathrm{mg}$ and $150 \mathrm{mg}$ versus the placebo control. SVR rates with simeprevir $75 \mathrm{mg}$ were $83.9 \%, 78.1 \%$, and $50.0 \%$, and with simeprevir $150 \mathrm{mg}$ were $97.1 \%, 80.0 \%$, and $66.7 \%$, respectively, for the $\mathrm{CC}$, $\mathrm{CT}$, and TT genotypes.

\section{Sofosbuvir}

The relationship between $I L 28 B$ polymorphisms and response to triple PEG-IFN/ribavirin-sofosbuvir therapy in treatment-naïve patients with $\mathrm{HCV}$ genotype 1 was investigated in the NEUTRINO trial (ClinicalTrials.gov registry number NCT01641640). ${ }^{60}$ The SVR rate in carriers of the $I L 28 B$ CC genotype was $98 \%$ and among carriers of the non-CC genotype was $87 \% .{ }^{69}$

IL28B genotyping is critical when considering triple therapy because DAAs are expensive and have many side effects. $I L 28 B$ genotyping can help physicians to decide whether triple therapy is necessary or if standard of care would be sufficient. Ahlenstiel et al ${ }^{100}$ suggest that triple therapy would be more beneficial for patients with the $I L 28 B$ nonresponder genotype, but the role of $I L 28 B$ polymorphisms may diminish with the development of newer and more effective DAAs. Genotyping HCV patients for $I L 28 B$ polymorphisms may be an important cost-effective screening method prior to triple therapy. Patients with a responder genotype can be assigned to treatment with PEG IFN/ribavirin. Retreatment with triple therapy should be considered in the event of relapse. Patients with nonresponder genotypes should be encouraged to start a triple therapy regimen. Null responders constitute a challenge because DAAs do not significantly improve response rates in this population and these patients should wait until more effective DAAs are developed.

\section{Role of IL28B in the outcome of a IFN-free regimen}

The predictive role of $I L 28 B$ was assessed in 83 patients with chronic hepatitis $\mathrm{C}$ assigned to either mericitabine (500 mg or 1,000 mg twice daily) plus danoprevir (100 mg or $200 \mathrm{mg}$ every 8 hours, or 600 or $900 \mathrm{mg}$ twice daily) or placebo. At day 14 (the end of IFN-free treatment), the mean reduction in serum HCV RNA levels was slightly greater in patients with the CC polymorphism (5.01 $\left.\log _{10} \mathrm{IU} / \mathrm{mL}\right)$ than in those without (4.59 $\left.\log _{10} \mathrm{IU} / \mathrm{mL}\right)$. Modeling showed that patients with the $\mathrm{CC}$ polymorphism had slightly better early viral kinetics. Patients with $\mathrm{CC}$ also had a better on-treatment response, suggesting that the $I L 28 B$ genotype has a positive influence on early viral kinetics in patients with chronic hepatitis $\mathrm{C}$ receiving IFN-free treatment. ${ }^{66}$

\section{IL28B polymorphisms in HCV/HIV coinfection}

Several studies ${ }^{101-109}$ have genotyped IL28B variants in patients coinfected with HCV and HIV. De Araujo et al ${ }^{101}$ demonstrated a strong association between the $\mathrm{G}$ allele and treatment failure. In contrast, the rs8099917 TT genotype was a strong predictor of treatment success, independent of baseline plasma HCV RNA loads or liver histology. This association was strongly evident in patients with genotype 1 but less obvious in patients with genotype 3 . In patients 
coinfected with HIV and HCV treated with PEG-IFN and ribavirin, the $I L 28 B$ CC genotype was detected in $75 \%$ of those with an SVR. ${ }^{101-108}$ The effectiveness of PEG-IFN $\alpha-2 \mathrm{a}$ in decreasing HCV RNA was greater during the first week of treatment in patients with the CC genotype than in those with the TT/TC genotype (for both genotype 1 and 3 ). Further, the second slower phase of viral decline was longer for genotype CC than for genotype TT/TC in patients with genotype 1 . The rs8103142 CT, rs12979860 CT, and rs11881222 AG genotypes were associated with a decrease in $\mathrm{HCV}$ clearance. ${ }^{101}$

In a cohort of HIV-1-infected Europeans recently infected with $\mathrm{HCV}$, Clausen et $\mathrm{al}^{103}$ reported spontaneous resolution in $23 \%$ of patients and chronic evolution in $77 \%$. The exonic rs8103142 CT genotype, the intronic rs11881222 AG genotype, and the haplotype block TCG CTA were associated with persistence of HCV. A significant difference in HCV RNA levels was found between rs8103142 and rs12979860 in individuals with chronic HCV genotype 1. Individuals with chronic HCV genotype 3 and with the favorable haplotype block CTA CTA had higher median HCV RNA levels than those with unfavorable haplotype blocks. Medrano et al ${ }^{106}$ developed and validated a noninvasive index including IL28B SNP rs12979860, liver stiffness, HCV genotype, and viral load to predict SVR in patients coinfected with HCV and HIV.

\section{IL28B polymorphism and liver transplantation}

Fukahara et al ${ }^{110}$ investigated whether recipient and donor genetic factors could predict the host response to PEG-IFN/ ribavirin therapy in the event of recurrent HCV infection. IL28B polymorphism (SNPs rs12980275 and rs8099917) was examined in $\mathrm{HCV}$-infected recipients and donors. A strong association was found between rs8099917 and SVR. Intrahepatic expression of IL28 messenger RNA was significantly lower in recipients and donors who carried the minor alleles (T/G or T/T) for rs8099917 ( $P=0.010$ and $P=0.009$, respectively). $I L 28 B$ polymorphism in the donor and recipient and HCV RNA mutation were good predictors of response to treatment. Another study ${ }^{11}$ examined rs12979860 C $>$ T SNP in patients with liver graft reinfection. Peak serum alanine aminotransferase and HCV RNA concentrations were higher in patients with the rs12979860 CC donor genotype than in those with the CT/TT genotypes. There were associations between donor IL28B rs12979860 CC versus CT/TT and rapid virologic response, complete early virologic response, and SVR, but these were not very strong.

\section{Relationship between other SNPs and} outcome of treatment for chronic HCV

Several recent studies have investigated the impact of various SNPs and the outcome of treatment for chronic HCV. One study $^{112}$ demonstrated a strong association between SNPs in the inosine triphosphate pyrophosphatase gene and ribavirin-induced hemolytic anemia in patients coinfected with HCV and HIV who were treated with PEG-IFN and ribavirin. Another study ${ }^{113}$ investigated the relationship between rs738409 PNPLA3 and development of hepatocellular carcinoma after antiviral therapy comprising PEG-IFN and ribavirin in Japanese patients with HCV serotype 1 and a high viral load.

\section{Pharmacogenomics and future HCV therapies}

Recent studies have suggested that PEG-IFN and ribavirin are likely to be supplanted soon by the addition of specifically targeted antiviral therapy for HCV (STAT-C). Resistance to new antivirals such as $\mathrm{HCV}$ protease inhibitors and emergence of potentially resistant strains of HCV are likely to develop. It is important to investigate the impact of the patient's genetic make-up on the response to STAT-C and development of resistance or emergence of adverse events. It is thus important to test the efficacy of various emerging antiviral combinations in various geographic areas, ethnic groups, HCV genotypes, and different stages of HCV infection. Stratifying patients enrolled in ongoing clinical trials according to IL-28B variations will help in tailoring future triple therapies.

\section{Pharmacogenomics in HCV infection: benefits and barriers}

Pharmacogenomics is a promising emerging field that provides insight into the impact of genetic variations on response of HCV patients to therapy. Pharmacogenomics offers potential clinical benefits to patients and economic benefits for health care delivery. This is crucial in the era of triple therapies and IFN-free regimens. DAAs are not only expensive but are genotype-specific and associated with development of resistance. Identifying individuals with a high chance of achieving an SVR will avoid failure of therapy and generation of unnecessary costs. Likewise, identifying chronic HCV patients at risk of accelerated liver fibrosis or development of hepatocellular carcinoma will help in prioritizing therapy for those patients to halt disease progression and prevent cirrhosis. Knowing upfront whether an individual may develop resistance to a DAA-containing regimen will enable the physician 
to select the appropriate therapy according to the needs of a specific patient. From the public health standpoint, treatment of acute infection will reduce the risk of transmission and prevent evolution of chronic disease.

Despite the advantages of pharmacogenomics in improving the outcome of HCV infection, several barriers and ethical concerns may delay the adoption of treatment algorithms based on genetic profiling of patients with HCV. Detecting gene variations is a somewhat complicated and expensive process that might not be easily available in developing countries with a heavy burden of HCV. Simpler affordable tests for detecting genetic variations are thus required to maximize the benefit of this technology.

To date, a limited number of drugs are approved for the treatment of chronic HCV infection. Thus, patients with gene variations associated with inadequate response may have no alternatives for treatment, leading to ethical concerns and debate. Would health insurance companies cover the costs of extra diagnostic genetic steps to determine eligibility for therapy? If a patient had an unfavorable genotype but other favorable pretreatment host and viral factors, would he or she be denied therapy and excluded from health insurance? If pretreatment genetic testing suggested that a particular individual had a high predisposition to adverse events, should this patient be denied treatment? Is pre-emptive treatment of adverse events possible or justified? What about the psychologic harm that may result from depriving an individual of treatment? Despite the potential role played by the individual's genetic make-up in determining the outcome of $\mathrm{HCV}$ infection, variation in drug response is not limited to micropolymorphisms or genes. Other host, viral, and environmental factors are likely to affect the safety and efficacy of therapy in particular individuals.

Requesting various genetic tests for different population subsets will undoubtedly complicate the process of drug prescribing. This complexity will require cooperation between disciplines to individualize health care. It is necessary for health providers to become more knowledgeable about the scope and limitations of genetic testing to be able to interpret results accurately and make informed decisions based on clinical factors as well as SNP genotyping. Health providers also need to reach out and communicate with their patients to clarify the impact of genes on response to therapy.

\section{HCV and pharmacogenomics in developing countries}

Pharmacogenomic applications may be important tools for individualizing the therapeutic options for $\mathrm{HCV}$, restricting
HCV transmission, halting the progression of chronic hepatitis, and ensuring that treatment is cost-effective. However, several questions persist. Should developing countries continue to act as end users for technology rather than be developers and innovators? The wide applications of pharmacogenomics seem an adequate setting for this argument, particularly in developing countries with a high prevalence of HCV and limited resources. Egypt could be a good candidate for pharmacogenomic applications in the field of HCV despite numerous challenges. The Egyptian government subsidizes the majority of health care services for HCV patients and failure to achieve an SVR represents wasted resources. Thus, prediction of treatment response seems a realistic approach to prioritize therapy for patients who are likely to respond.

In conclusion, pharmacogenomics offers the potential to tailor HCV therapy to increase the effectiveness of existing and new therapies, minimize adverse events, and maximize the cost-benefit of health interventions for this infection, given its vast impact on public health globally. Emerging data suggest that treatment for HCV could be individualized according to the genetic profile of the patient, pretreatment host, viral characteristics, and viral kinetics on treatment. As genomics technology becomes more common in both developed western countries and low-income to middleincome countries, the landscape of health care services and delivery will also change, with equitable and timely genomics applications for diseases such as HCV infection affecting the global society.

\section{Disclosure}

The author reports no conflicts of interest in this work.

\section{References}

1. World Health Organization. Hepatitis C. WHO fact sheet 164. Geneva, Switzerland: World Health Organization; 2000. Available from: http://www. who.int/mediacentre/factsheets/fs164/en/. Accessed April 28, 2014.

2. Armstrong GL, Wasley A, Simard EP, et al. The prevalence of hepatitis C virus infection in the United States, 1999 through 2002. Ann Intern Med. 2006;144(10):705-714.

3. Desenclos JC. The challenge of hepatitis C surveillance in Europe. Euro Surveill. 2003;8(5):99-110.

4. Lavanchy D. The global burden of hepatitis C. Liver Int. 2009; 29 Suppl 1:74-81.

5. Egyptian Ministry of Health. Annual Report 2007. Available from: http:// www.mohp.gov.eg/Main.asp. Accessed October 13, 2013.

6. Lehman EM, Wilson ML. Epidemic hepatitis C virus infection in Egypt: estimates of past incidence and future morbidity and mortality. $J$ Viral Hepat. 2009;16(9):650-658.

7. Micallef JM, Kaldor JM, Dore GJ. Spontaneous viral clearance following acute hepatitis $\mathrm{C}$ infection: a systematic review of longitudinal studies. J Viral Hepat. 2006;13(1):34-41.

8. Hoofnagle JH. Course and outcome of hepatitis C. Hepatology. 2002; 36(5 Suppl 1):S21-S29. 
9. Seeff LB. The natural history of chronic hepatitis $\mathrm{C}$ virus infection. Clin Liver Dis. 1997;1(3):587-602.

10. Sen GC. Viruses and interferons. Annu Rev Microbiol. 2001;55: 255-281.

11. Tilg $\mathrm{H}$. New insights into the mechanisms of interferon alfa: an immunoregulator and anti-inflammatory cytokine. Gastroenterology. 1997;112(3):1017-1021.

12. Foster GR. Review article: PEGylated interferons: chemical and clinical differences. Aliment Pharmacol Ther. 2004;20(8):825-830.

13. Pestka S. The human interferon alpha species and receptors. Biopolymers. 2000;55(4):254-287.

14. Wohnsland A, Hofmann WP, Sarrazin C. Viral determinants of resistance to treatment in patients with hepatitis C. Clin Microbiol Rev. 2007; 20(1):23-38.

15. Feld JJ, Hoofnagle JH. Mechanism of action of interferon and ribavirin in treatment of hepatitis C. Nature. 2005;436(7053):967-972.

16. Lau JY, Tam RC, Liang TJ, Hong Z. Mechanism of action of ribavirin in the combination treatment of chronic $\mathrm{HCV}$ infection Hepatology. 2002;35(5):1002-1009.

17. Kamal SM, Ismail A, Graham CS, et al. PEGylated interferon a therapy in acute hepatitis $\mathrm{C}$ : relation to hepatitis $\mathrm{C}$ virus specific $\mathrm{T}$ cell response kinetics. Hepatology. 2004;39(6):1721-1731.

18. Kamal SM, Fouly AE, Kamel RR, et al. PEG-interferon alfa-2b therapy in acute hepatitis $\mathrm{C}$ : impact of onset of therapy on sustained virologic response. Gastroenterology. 2006;130(3):632-638.

19. Kamal SM, Moustafa KN, Chen J, et al. Duration of PEGinterferon therapy in acute hepatitis C: a randomized trial. Hepatology. 2006;43(5): 923-931.

20. Wiegand J, Buggisch P, Boecher W, et al. Early monotherapy with PEGylated interferon alpha-2b for acute hepatitis $\mathrm{C}$ infection: the HEP-NET acute-HCV-II study. Hepatology. 2006;43(2):250-256.

21. De Rosa FG, Bargiacchi O, Audagnotto S, et al. Dose-dependent and genotype-independent sustained virological response of a 12 week PEGylated interferon alpha- $2 \mathrm{~b}$ treatment for acute hepatitis C. J Antimicrob Chemother. 2006;57(2):360-363.

22. Calleri G, Cariti G, Gaiottino F, et al. A short course of PEGylated interferon-alpha in acute HCV hepatitis. J Viral Hepat. 2007;14(2): 116-121.

23. De Rosa FG, Bargiacchi O, Audagnotto S, et al. Twelve week treatment of acute hepatitis $\mathrm{C}$ virus with PEGylated interferon- alpha $-2 \mathrm{~b}$ in injection drug users. Clin Infect Dis. 2007;45(5):583-538.

24. Kamal SM, Kassim SK, Ahmed AI, et al. Host and viral determinants of the outcome of exposure to HCV infection genotype 4: a large longitudinal study. Am J Gastroenterol. 2014;109(2):199-211.

25. Santantonio T, Medda E, Ferrari C, et al. Risk factors and outcome among a large patient cohort with community-acquired acute hepatitis $\mathrm{C}$ in Italy. Clin Infect Dis. 2006;43(9):1154-1159.

26. Jonas M. Children with hepatitis C. Hepatology. 2002;36(5): S173-S178.

27. Bakr I, Rekacewicz C, El Hosseiny M, et al. Higher clearance of hepatitis $\mathrm{C}$ virus infection in females compared with males. Gut. 2006;55(8):1183-1187.

28. Kamal SM, Amin A, Madwar M, et al. Cellular immune responses in seronegative sexual contacts of acute hepatitis C patients. $J$ Virol. 2004;78(22):12252-12258.

29. Farci P, Strazzera R, Alter HJ, et al. Early changes in hepatitis C viral quasispecies during interferon therapy predict the therapeutic outcome. Proc Natl Acad Sci U S A. 2002;99(5):3081-3086.

30. Danta M, Brown D, Bhagani S, et al. Recent epidemic of acute hepatitis $C$ virus in HIV-positive men who have sex with men linked to high risk sexual behaviors. AIDS. 2007;21(8):983-991.

31. Luetkemeyer A, Hare CB, Stansell J, et al. Clinical presentation and course of acute hepatitis $\mathrm{C}$ infection in HIV-infected patients. $J$ Acquir Immune Defic Syndr. 2006;41(1):31-36.

32. Angelico M, Renganathan E, Gandin C, et al. Chronic liver disease in the Alexandria governorate, Egypt: contribution of schistosomiasis and hepatitis virus infections. J Hepatol. 1997;26(2):236-243.
33. Kamal S, Madwar M, Bianchi L, et al. Clinical, virological and histopathological features: long-term follow-up in patients with chronic hepatitis C co-infected with S. mansoni. Liver. 2000;20(4):281-289.

34. Kamal SM, Rasenack JW, Bianchi L, et al. Acute hepatitis $C$ without and with schistosomiasis: correlation with hepatitis C-specific CD4(+) T-cell and cytokine response. Gastroenterology. 2001;121(3):646-656.

35. Kamal SM, Turner B, He Q, et al. Progression of fibrosis in hepatitis C with and without schistosomiasis: correlation with serum markers of fibrosis. Hepatology. 2006;43(4):771-779.

36. Wells JT, Lucey MR, Said A. Hepatitis C in transplant recipients of solid organs, other than liver. Clin Liver Dis. 2006;10(4):901-917.

37. Shoukry NH, Cawthon AG, Walker CM. Cell-mediated immunity and the outcome of hepatitis C virus infection. Annu Rev Microbiol. 2004;58:391-424.

38. Lechner F, Wong DK, Dunbar PR, et al. Analysis of successful immune responses in persons infected with hepatitis C virus. $J$ Exp Med. 2000;191(9):1499-1512.

39. Thimme R, Oldach D, Chang KM, et al. Determinants of viral clearance and persistence during acute hepatitis $\mathrm{C}$ virus infection. $J$ Exp Med. 2001;194(1):1395-1406.

40. Lechner F, Gruener NH, Urbani S, et al. CD8+T lymphocyte responses are induced during acute hepatitis $\mathrm{C}$ virus infection but are not sustained. Eur J Immunol. 2000;30(9):2479-2487.

41. Khakoo SI, Thio CL, Martin MP, et al. HLA and natural killer cell inhibitory receptor genes in resolving hepatitis $\mathrm{C}$ virus infection. Science. 2004;305(5685):872-874.

42. An P, Thio CL, Kirk GD, et al. Regulatory polymorphisms in the interleukin-18 promoter are associated with hepatitis $\mathrm{C}$ virus clearance. J Infect Dis. 2008;198(8):1159-1165.

43. Donnelly RP, Kotenko SV. Interferon-lambda: a new addition to an old family. J Interferon Cytokine Res. 2010;30(8):555-564.

44. Thomas DL, Thio CL, Martin MP, et al. Genetic variation in IL28B and spontaneous clearance of hepatitis C virus. Nature. 2009; 461(7265):798-801.

45. Rauch A, Kutalik Z, Descombes P. Genetic variation in IL28B is associated with chronic hepatitis $\mathrm{C}$ and treatment failure: a genome-wide association study. Gastroenterology. 2010;138(4):1338-1345.

46. Grebely J,Petoumenos K, Hellard M, etal. Potential role for interleukin-28B genotype in treatment decision-making in recent hepatitis $\mathrm{C}$ virus infection. Hepatology. 2010;52(4):1216-1224.

47. Ge D, Fellay J, Thompson A, et al. Genetic variation in IL28B predicts hepatitis C treatment-induced viral clearance. Nature. 2009;461(7262): 399-401.

48. Tillmann HL, Thompson AJ, Patel K, et al. A polymorphism near IL28B is associated with spontaneous clearance of acute hepatitis $\mathrm{C}$ virus and jaundice. Gastroenterology. 2010;139(5):1586-1592.

49. Asselah T, Estrabaud E, Bieche I, et al. Hepatitis C: viral and host factors associated with non-response to PEGylated interferon plus ribavirin. Liver Int. 2010;30(9):1259-1269.

50. Kamal S, Kamary S, Shardell M, et al. PEGylated interferon alpha-2b plus ribavirin in patients with genotype 4 chronic hepatitis C: the role of rapid and early virologic response. Hepatology. 2007;46(6): $1732-1740$

51. Ferenci P, Laferl H, Scherzer TM, et al. Peginterferon alfa-2a and ribavirin for 24 weeks in hepatitis $\mathrm{C}$ type 1 and 4 patients with rapid virological response. Gastroenterology. 2008;135(2):451-458.

52. Kamal S, Ahmed A, Mahmoud S, et al. Enhanced efficacy of pegylated interferon alfa-2a plus ribavirin over pegylated interferon alfa- $2 b$ plus ribavirin in the treatment of patients with chronic hepatitis $\mathrm{C}$ genotype 4 : a randomized trial and health-related quality of life analysis. Liver Int. 2011;31(3):401-411.

53. Mangia A, Santoro R, Minerva N, et al. Peginterferon alfa- $2 b$ and ribavirin for 12 vs 24 weeks in HCV genotype 2 or 3. $N$ Engl J Med. 2005;352(25):2609-2617.

54. Shiffman ML, Suter F, Bacon BR et al. Peginterferon alfa-2a and ribavirin for 16 or 24 weeks in HCV genotype 2 or 3. $N$ Engl J Med. 2007;357(2):124-134. 
55. Lo Re V 3rd, Amorosa VK, Localio AR, et al. Adherence to hepatitis C virus therapy and early virologic outcomes. Clin Infect Dis. 2009;48(2): 186-193.

56. Fried MW, Shiffman ML, Reddy KR, et al. Peginterferon alfa-2a plus ribavirin for chronic hepatitis $\mathrm{C}$ virus infection. $N$ Engl $J$ Med. 2002;347(13):975-982.

57. Manns MP, McHutchison JG, Gordon SC, et al. Peginterferon alfa-2b plus ribavirin compared with interferon alfa- $2 \mathrm{~b}$ plus ribavirin for initial treatment of chronic hepatitis C: a randomised trial. Lancet. 2001;358(9286):958-965.

58. Jensen DM, Morgan TR, Marcellin P, et al. Early identification of HCV genotype 1 patients responding to 24 weeks peginterferon alpha-2a $(40 \mathrm{kd})$ /ribavirin therapy. Hepatology. 2006;43(5):954-960.

59. Zeuzem S, Buti M, Ferenci P, et al. Efficacy of 24 weeks treatment with peginterferon alfa- $2 \mathrm{~b}$ plus ribavirin in patients with chronic hepatitis $\mathrm{C}$ infected with genotype 1 and low pretreatment viremia. $J$ Hepatol. 2006;44(1):97-103.

60. Lukasiewicz E, Gorfine M, Freedman LS, et al. Prediction of non SVR to therapy with PEGylated interferon-alpha $2 \mathrm{a}$ and ribavirin in chronic hepatitis $C$ genotype 1 patients after 4,8 and 12 weeks of treatment. J Viral Hepat. 2010;17(5):345-351.

61. Jacobson IM, Catlett I, Marcellin P, et al. Telaprevir substantially improved SVR rates across all Il28b genotypes in the advance trial. J Hepatol. 2011;54:S542-S543.

62. Poordad F, Bronowicki JP, Gordon SC, et al. Il28b polymorphism predicts virologic response in patients with hepatitis $\mathrm{C}$ genotype 1 treated with boceprevir (BOC) combination therapy. J Hepatol. 2011; 54 Suppl 1:S6

63. European Association for the Study Of the Liver. EASL Clinical Practice Guidelines: Management of hepatitis C virus infection. Available from: http://www.easl.eu/assets/application/files/bdb06ff135c7ccb_file.pdf. Accessed April 28, 2014.

64. Asselah T, Marcellin P. Second-wave IFN-based triple therapy for HCV genotype 1 infection: simeprevir, faldaprevir and sofosbuvir. Liver Int. 2014;34 Suppl 1:60-68.

65. Fried MW, Buti M, Dore GJ, et al. Once-daily simeprevir (TMC435) with pegylated interferon and ribavirin in treatment-naïve genotype 1 hepatitis C: the randomized PILLAR study. Hepatology. 2013;58(6): 1918-1929.

66. Marcellin P, Cooper C, Balart L. Randomized controlled trial of danoprevir plus peginterferon alfa-2a and ribavirin in treatment-naïve patients with hepatitis C virus genotype 1 infection. Gastroenterology. 2013;145(4):790-800.

67. Everson G, Cooper C, Hézode C et al. DAUPHINE: a randomized phase II study of danoprevir/ritonavir plus peginterferon alpha-2a/ribavirin in HCV genotypes 1 or 4. Liver Int. January 19, 2014. [Epub ahead of print.]

68. Ilyas JA, Vierling JM. An overview of emerging therapies for the treatment of chronic hepatitis C. Med Clin North Am. 2014;98(1):17-38.

69. Lawitz E, Mangia A, Wyles D, et al. Sofosbuvir for previously untreated chronic hepatitis C infection. $N$ Engl J Med. 2013;368(20): $1878-1887$.

70. Kowdley KV, Lawitz E, Crespo I, et al. Sofosbuvir with pegylated interferon alfa-2a and ribavirin for treatment-naive patients with hepatitis C genotype-1 infection (ATOMIC): an open-label, randomised, multicentre phase 2 trial. Lancet. 2013;381(9883):2100-2107.

71. Gane EJ, Stedman CA, Hyland RH, et al. Efficacy of nucleotide polymerase inhibitor sofosbuvir plus the NS5A inhibitor ledipasvir or the NS5B non-nucleoside inhibitor GS-9669 against HCV genotype 1 infection. Gastroenterology. 2014;146(3):736-743. e1.

72. Lawitz E, Poordad FF, Pang PS, et al. Sofosbuvir and ledipasvir fixeddose combination with and without ribavirin in treatment-naive and previously treated patients with genotype 1 hepatitis $\mathrm{C}$ virus infection (LONESTAR): an open-label, randomised, phase 2 trial. Lancet. 2014;383(9916):515-523

73. Afdhal NH, McHutchison JG,ZeuzemS, etal. Hepatitis Cpharmacogenetics: state of the art in 2010. Hepatology. 2011;53(1):336-345.
74. Tanaka Y, Nishida N, Sugiyama M, et al. Genome-wide association of IL28B with response to pegylated interferon- $\alpha$ and ribavirin therapy for chronic hepatitis C. Nat Genet. 2009;41(10):1105-1110.

75. Suppiah V, Moldovan M, Ahlenstiel G, et al. IL28B is associated with response to chronic hepatitis $\mathrm{C}$ interferon- $\alpha$ and ribavirin therapy. Nat Genet. 2009;41(10):1100-1104.

76. Ito K, Higami K, Masaki N, et al. The rs 8099917 polymorphism, determined by a suitable genotyping method, is a better predictor for response to PEGylated alpha interferon/ribavirin therapy in Japanese patients than other SNPs associated with IL28B. J Clin Microbiol. 2011;49(5):1853-1860

77. Darling JM, Aerssens J, Fanning G, et al. Quantitation of pretreatment serum interferon- $\gamma$-inducible protein-10 improves the predictive value of an IL28B gene polymorphism for hepatitis C treatment response. Hepatology. 2011;53(1):14-22.

78. Lagging M, Askarieh G, Negro F, et al. Response prediction in chronic hepatitis $\mathrm{C}$ by assessment of IP-10 and IL28B-related single nucleotide polymorphisms. PLoS One. 2011;24;6(2):17232.

79. Honda M, Sakai A, Yamashita T. Hepatic ISG expression is associated with genetic variation in interleukin $28 \mathrm{~B}$ and the outcome of IFN therapy for chronic hepatitis C. Gastroenterology. 2010;139(2):499-509.

80. Urban TJ, Thompson AJ, Bradrick SS. IL28B genotype is associated with differential expression of intrahepatic interferon-stimulated genes in patients with chronic hepatitis C. Hepatology. 2010;52(6): 1888-1896.

81. Mangia A, Thompson AJ, Santoro R, et al. An IL28B polymorphism determines treatment response of hepatitis $\mathrm{C}$ virus genotype 2 or 3 patients who do not achieve a rapid virologic response. Gastroenterology. 2010;139(3):821-827.

82. Asselah T, De Muynck S, Broët P, et al. IL-28B polymorphism is associated with treatment response in patients with genotype 4 chronic hepatitis C. J Hepatol. 2012;56(3):527-532.

83. Derbala M, Rizk NM, Al-Kaabi S, et al. The predictive value of IL28B rs12979860, rs11881222 and rs8099917 polymorphisms and IP-10 in the therapeutic response of Egyptian genotype 4 patients. Virology. 2013;444(1-2):292-300.

84. Thompson AJ, Muir AJ, Sulkowski MS, et al. Interleukin-28B polymorphism improves viral kinetics and is the strongest pretreatment predictor of sustained virologic response in genotype 1 hepatitis $\mathrm{C}$ virus. Gastroenterology. 2010;139(1):120-129.

85. McCarthy JJ, Li JH, Thompson A, et al. Replicated association between an IL-28B gene variant and a sustained response to PEGylated interferon and ribavirin. Gastroenterology. 2010;138(7):2307-2314.

86. Hayes CN, Kobayashi M, Akuta N, et al. HCV substitutions and IL-28B polymorphisms on outcome of peg-interferon plus ribavirin combination therapy. Gut. 2011;60(2):261-267.

87. Stättermayer AF, Strassl R, Maieron A, et al. Polymorphisms of interferon- $\lambda 4$ and IL-28B - effects on treatment response to interferon/ ribavirin in patients with chronic hepatitis C. Aliment Pharmacol Ther. 2014;39(1):104-111.

88. Sarrazin C, Susser S, Doehring A, et al. Importance of gene polympriphisms in hepatitis $\mathrm{C}$ virus genotypes 2 and 3 infected patients. $J$ Hepatol. 2011;54(3):415-421.

89. Kurosaki M, Tanaka Y, Nishida N, et al. Pre-treatment prediction of response to pegylated interferon plus ribavirin for chronic hepatitis $\mathrm{C}$ using genetic polymorphism in IL28B and viral factors. $J$ Hepatol. 2011;54(3):439-448.

90. Montes-Cano MA, Garcia-Lozano JR, Abad-Molina C, et al. Interleukin- 28B genetic variants and hepatitis virus infection by different viral genotypes. Hepatology. 2010;52(1):33-37.

91. Kawaoka T, Hayes CN, Ohishi W, et al. Predictive value of the IL28B polymorphism on the effect of interferon therapy in chronic hepatitis $\mathrm{C}$ patients with genotypes 2a and 2b. J Hepatol. 2011;54(3):408-414.

92. Scherzer TM, Hofer H, Staettermayer AF, et al. Early virologic response and IL28B polymorphisms in patients with chronic hepatitis $\mathrm{C}$ genotype 3 treated with peginterferon alfa-2a and ribavirin. $J$ Hepatol. 2011;54(5):866-871. 
93. Scherzer TM, Stättermayer AF, Strasser M, et al. Impact of IL28B on treatment outcome in hepatitis $\mathrm{C}$ virus $\mathrm{G} 1 / 4$ patients receiving response-guided therapy with peginterferon alpha-2a (40KD)/ribavirin. Hepatology. 2011;54(5):1518-1526.

94. Pol S, Aerssens J, Zeuzem S, et al. Similar SVR rates in Il-28b CC, CT or TT prior relapser, partial- or null-responder patients treated with telaprevir/peginterferon/ribavirin: retrospective analysis of the REALIZE study. J Hepatol. 2011;54:S6-S7.

95. Chayama K, Hayes CN, Abe H, et al. IL28B but not ITPA polymorphism is predictive of response to PEGylated interferon, ribavirin, and telaprevir triple therapy in patients with genotype 1 hepatitis $\mathrm{C}$. J Infect Dis. 2011;204(1):84-93.

96. Bronowicki JP, Hezode C, Bengtsson L, et al. 100\% SVR in IL28B $\mathrm{CC}$ patients treated with 12 weeks of telaprevir, peginterferon and ribavirin in the PROVE2 trial [abstract]. J Hepatol. 2012;56 Suppl 2: S430.

97. Akuta N, Suzuki F, Seko Y, et al. Determinants of response to triple therapy of telaprevir, peginterferon, and ribavirin in previous nonresponders infected with HCV genotype 1. J Med Virol. 2012;84(7): 1097-1105.

98. Bota S, Sporea I, Sirli R, Neghina AM, Popescu A, Strain M. Role of interleukin-28B polymorphisms as a predictor of sustained virological response in patients with chronic hepatitis $\mathrm{C}$ treated with triple therapy: a systematic review and meta-analysis. Clin Drug Investig. 2013;33(5):325-331.

99. Furusyo N, Ogawa E, Nakamuta M, et al. Telaprevir can be successfully and safely used to treat older patients with genotype $1 \mathrm{~b}$ chronic hepatitis C. J Hepatol. 2013;59(2):205-212.

100. Ahlenstiel G, Booth DR, George J. Will IL28B polymorphisms remain relevant to direct-acting antiviral treatment paradigms? Antivir Ther. 2012;17(6 Pt B):1163-1170.

101. De Araujo ES, Dahari H, Cotler SJ, et al. Pharmacodynamics of PEG-IFN alpa-2a and HCV response as a function of IL-28B polymorphism in HIV/HCV coinfected patients. J Acquir Immune Defic Syndr. 2011;56(2):95-99.

102. Rivero-Juarez A, Lopez-Cortes LF, Camacho A, et al. The IL28B effect on hepatitis $\mathrm{C}$ virus kinetics among HIV patients after the first weeks of pegylated-interferon/ribavirin treatment varies according to hepatitis C virus-1 subtype. AIDS. 2013;27(12):1941-1947.
103. Clausen LN, Weis N, Astvad K, et al. Interleukin-28B polymorphisms are associated with hepatitis $\mathrm{C}$ virus clearance and viral load in a HIV-1-infected cohort. J Viral Hepat. 2011;18(4):66-74.

104. Rallon NI, Naggie S, Benito GM, et al. Association of a single nucleotide polymorphism near the interleukin $28 \mathrm{~B}$ gene with response to hepatitis $\mathrm{C}$ therapy in HIV hepatitis $\mathrm{C}$ virus coinfected patients. AIDS. 2010;24(8):23-29.

105. Aparicio E, Parera M, Franco S, et al. IL 28B SNP rs8099917 is strongly associated with PEGylated interferon alpha and ribavirin therapy treatment failure in $\mathrm{HCV} / \mathrm{HIV}$ I coinfected patients. PLoS One. 2010;5(10):1-5

106. Medrano J, Neukam K, Rallón N. Modeling the probability of sustained virological response to therapy with PEGylated interferon plus ribavirin in patients coinfected with hepatitis $\mathrm{C}$ virus and HIV. Clin Infect Dis. 2010;51(10):1209-1216.

107. Pineda JA, Caruz A, Rivero A, et al. Prediction of response to pegylated interferon plus ribavirin by IL28B gene variation in patients coinfected with HIV and hepatitis C virus. Clin Infect Dis. 2010;51(7):788-795.

108. Nattermann J, Vogel M, Nischalke HD, et al. Genetic variation in IL28B and treatment-induced clearance of hepatitis C virus in HIVpositive patients with acute and chronic hepatitis C. J Infect Dis. 2011;203(5):595-601.

109. Labarga P, Soriano V, Caruz A, et al. Association between IL28B gene polymorphisms and plasma HCV-RNA levels in HIV/HCV-co-infected patients. AIDS. 2011;25(8):1131-1133.

110. Fukuhara T, Taketomi A, Motomura T, et al. Variance in IL 28B in liver recipients and donors correlate with response to PEG-Interferon and ribavirin therapy for recurrent hepatitis C. Gastroenterology 2010;139(5):1577-1585.

111. Lange CM, Moradpour D, Doehring A. Impact of donor and recipient IL-28 B rs12979860 genotypes in hepatitis C virus liver graft reinfection. J Hepatol. 2011;55(2):322-327.

112. Osinusi A, Naggie S, Poonia S. ITPA Gene polymorphisms significantly affect hemoglobin decline and treatment outcomes in patients coinfected with HIV and HCV. J Med Virol. 2012;84(7):1106-1114.

113. Yuki Moritou Y, Ikeda F, Iwasaki Y. Predictive impact of polymorphism of PNPLA3 on HCC development after interferon therapy in Japanese patients with chronic hepatitis C. Springerplus. 2013;2(1):251.
Hepatic Medicine: Evidence and Research

\section{Publish your work in this journal}

Hepatic Medicine: Evidence and Research is an international, peerreviewed, open access journal covering all aspects of adult and pediatric hepatology in the clinic and laboratory including the following topics: Pathology, pathophysiology of hepatic disease; Investigation and treatment of hepatic disease; Pharmacology of drugs used for

\section{Dovepress}

the treatment of hepatic disease. Issues of patient safety and quality of care will also be considered. The manuscript management system is completely online and includes a very quick and fair peer-review system, which is all easy to use. Visit http://www.dovepress.com/ testimonials.php to read real quotes from published authors. 